\title{
Articulação e encaminhamento das questões da pesca artesanal: uma análise do fórum da pesca do litoral norte do Rio Grande do Sul, Brasil *
}

\author{
Articulation and referral issues of artisanal fishery: \\ an analysis of the fishing forum of litoral norte do Rio Grande do Sul, Brazil
}

\author{
L. C. Perucchi ${ }^{\circledR, 1}$, R. R. Kubo ${ }^{2}$, G. Coelho-de-Souza ${ }^{2}$
}

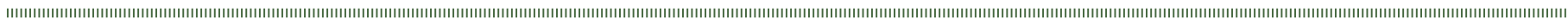

\section{RESUMO}

Os Fóruns de Pesca são arranjos institucionais que surgem a partir de uma organização popular e estão inseridos numa ótica descentralizada de gestão, compreendida como gestão compartilhada. No Rio Grande do Sul, existem algumas iniciativas de sistemas de gestão compartilhada da pesca artesanal, a partir de Fóruns da Pesca, sendo o Fórum do Litoral Norte um dos espaços de gestão de maior organização. Este artigo tem como objetivo analisar a gestão no Fórum da Pesca do Litoral Norte do Rio Grande do Sul, com ênfase em sua capacidade de articulação e encaminhamento das questóes da pesca profissional artesanal em ambientes lagunares, estuarinos e marítimos. A metodologia constou de um estudo de caso, a partir de uma abordagem qualitativa e a análise dos dados foi realizada a partir da análise de conteúdo. Realizou-se pesquisa-açáo, cuja coleta de dados ocorreu em dois espaços de análise, nas reuniôes gerais do Fórum da Pesca, em 2011 e 2012, e nos encontros promovidos com os pescadores artesanais, com objetivo de identificar os problemas e demandas da pesca artesanal. Os assuntos debatidos nos três encontros foram sistematizados em torno dos temas: pesca em ambientes lagunares e estuarinos (questôes ambientais, fiscalização, legislação ambiental, conflitos territoriais e com outras categorias de usuários) e marítimos (questóes ambientais e conflitos territoriais) e questóes gerais dos pescadores profissionais artesanais (burocracia para documentação e acesso a programas e valorização da pesca artesanal). As questóes da pesca profissional artesanal identificadas no espaço dos encontros estavam em consonância com os temas comumente debatidos e encaminhados no espaço do Fórum de Pesca do Litoral Norte. Dentre as questóes identificadas nos encontros com os pescadores, sobre as quais já existe uma articulação e encaminhamento no âmbito do Fórum, destacam-se: a) das ambientais, a situação das comportas e do derramamento de óleo; b) de fiscalização e legislação, a capacitação dos fiscais, a revisão dos critérios técnicos para o ordenamento pesqueiro e o ordenamento da orla marítima; c) das burocráticas, esclarecimentos sobre documentação para a pesca profissional artesanal e revisão de acordos com prefeituras sobre a pesca no verão. Com o surgimento do Fórum de Pesca do Litoral Norte criou-se a possibilidade de um diálogo direto com entidades governamentais e o encaminhamento de demandas identificadas pelas comunidades pesqueiras. No entanto, este Fórum apesar de ser considerado o mais organizado comparado aos demais que existem no Rio Grande do Sul, ainda está em processo contínuo de estruturação, o que acarreta em falhas durante o processo. Conclui-se que o Fórum de Pesca do Litoral Norte do Rio Grande do Sul é um espaço de implementação

@- Corresponding author: loyvanac@hotmail.com

1 - Núcleo de Estudos em Desenvolvimento Rural Sustentável e Mata Atlântica (DESMA) e Universidade Federal do Rio Grande do Sul, Programa de PósGraduação em Desenvolvimento Rural.

2 - Universidade Federal do Rio Grande do Sul, Departamento de Economia e Relaçóes Internacionais, Programa de Pós-Graduação em Desenvolvimento Rural, Núcleo de Estudos em Desenvolvimento Rural Sustentável e Mata Atlântica, DESMA; Núcleo de Estudos e Pesquisas em Segurança Alimentar e Nutricional, NESAN; Av. João Pessoa 31 90040-000 Porto Alegre, Brasil. e-mails: Coelho-de-Souza-gabriela.coelho@pesquisador.cnpq.br 
da gestâo compartilhada, o qual foi incentivado pelo governo e apropriado pela representaçáo dos pescadores, tendo a capacidade de articular as demandas dos pescadores artesanais de ambientes lagunares, estuarinos e marítimos da região do Litoral Norte e encaminhar às instâncias competentes. Entretanto, por serem demandas associadas à gestão de recursos comuns e territórios compartilhados, os quais estão sendo apropriados por segmentos da sociedade respaldados pela lógica da propriedade privada, elas são tensionadas pelo arranjo institucional envolvido na gestão compartilhada, estando, atualmente, em disputa na sociedade.

Palavras-chave: Gestão compartilhada, pescadores profissionais artesanais, pesca lagunar, pesca estuarina, pesca marítima, Fórum de Pesca.

\section{ABSTRACT}

The Fishing Forums are institutional arrangements that arise from a grassroots organization and are inserted in a decentralized management perspective, understood as shared management. In Rio Grande do Sul, there are some initiatives management systems shared fishing from Forum Fisheries Forum and the North Coast of the largest spaces management organization. This article aims to analyze the management of Forum Fishing the North Coast of Rio Grande do Sul, with emphasis on their ability to articulate the issues and routing of professional fishing craft in lagoon environments, estuarine and marine. The methodology consisted of a case study, based on a qualitative approach and data analysis was performed based on content analysis. We carried out action research, which data collection occurred in two areas of analysis, general meetings of the Forum Fisheries in 2011 and 2012, and in workshops sponsored with artisanal fishermen, in order to identify the problems and demands of fishing craft. The issues discussed in three meetings were organized around the themes: fishing in lagoons and estuarine environments (environmental issues, surveillance, environmental legislation, land conflicts and other categories of users) and sea (territorial conflicts and environmental issues) and general issues of traditional fishermen (bureaucracy for documentation and access to programs and artisanal fisheries enhancement). The professional artisanal fisheries issues identified within the meetings were in line with the commonly debated topics in space and forwarded Forum Fishing the North Coast. Among the issues identified in meetings with fishermen, on which there is already a linkage and referral within the Forum, are: a) the environmental situation of the gates and the oil spill, b) monitoring and legislation, training of tax, revision of technical criteria for fishery management and planning of the waterfront c) of bureaucratic documentation for clarification on professional fishing craft and revision of agreements with municipalities about fishing in the summer. With the emergence Forum Fishing the North Coast created the possibility of a direct dialogue with government entities and the routing of demands identified by the fishing communities. However, this forum despite being considered the more organized compared to the others that exist in Rio Grande do Sul, is still ongoing process of structuring, resulting in failure during the process. We conclude that the Forum Fishing the North Coast of Rio Grande do Sul is an area of shared management implementation, which was encouraged by the government and by the appropriate representation of fishermen, having the ability to articulate the demands of fishermen environments lagustres, estuarine and marine region of the North Coast and refer to the relevant bodies. However, demands for being associated with management of common resources and shared territories, which are being appropriated by segments of society backed by the logic of private property, they are fastened by institutional arrangements involved in shared management and is currently in dispute in society.

Keywords: Management shared, traditional fishermen, fishing lagoon, estuary fishing, sea fishing, Fishing Forum.

\section{INTRODUÇÃO}

A gestão compartilhada de recursos de uso comum é entendida como a divisão de poder, entre Estado e grupos de interesse, nas decisóes sobre o gerenciamento destes recursos (Carlsson \& Berkes, 2005). Representam um mecanismo institucional com potencial para reverter o processo de centralização e incorporar o conhecimento ecológico tradicional dos pescadores artesanais, os quais dependem exclusivamente do recurso e são os principais afetados pelas decisões, no processo de uso e gerenciamento da pesca (Kalikoski et al, 2006).

Em diversos países existem experiências de gestáo com o compartilhamento de decisões. A exemplo, Berkes (2005) estudando a pesca na costa sul da Turquia, observou alguns casos de arranjos institucionais de gestão dos recursos pesqueiros nos quais os pescadores tiveram participação. Esta participação ocorreu em graus diferentes, desde uma mera consulta pelo governosobreosinteressese propostas feitas pelos usuários, até o manejo totalmente comunitário planejado e implementado pelas comunidades com participação mínima do governo. Outra iniciativa de gestão compartilhada foi observada na ilha caribenha de Santa Lúcia por Smith \&
Berkes (2005), que apresentam os resultados do projeto de conservação dos recursos do manguesal Mankótè, utilizados por pequenos produtores de carvão vegetal, iniciativa esta que se baseou no fortalecimento da organização dos usuários locais e de seus direitos de uso dos recursos e na formação de instituiçóes de propriedade comunal.

No Brasil a gestão compartilhada tem aumentado em iniciativas, sendo que são encontrados avanços na legislação referente à gestão dos recursos naturais, que vem incluindo a população de usuários destes recursos (Kalikoski et al, 2006). Algumas políticas públicas brasileiras evidenciam a necessidade da participação das populaçóes locais nas tomadas de decisóes, como por exemplo o Plano Nacional de Gerenciamento Costeiro implementado pela Lei $\mathrm{n}^{\circ}$ 7.661/88 (D.O.U., 1988) e o Sistema Nacional de Unidades de Conservação, Lei n 9985/2000 (D.O.U., 2000).

No entanto, apenas em 2009 foram criados instrumentos jurídicos para legitimar estes espaços de gestão compartilhada. Essa importante legislação pode ser observada no Decreto $\mathrm{n}^{\circ}$ 6.981/2009 (D.O.U., 2009a), que dispôe sobre a atuação conjunta dos Ministérios da Pesca e Aquicultura e do Meio Ambiente nos aspectos relacionados ao uso sustentável dos recursos pesqueiros, e na Portaria Interministerial MMA/ 
MPA n 2/2009 (D.O.U., 2009b), que regulamenta e orienta os processos de gestão compartilhada no Brasil.

A Portaria Interministerial define gestão compartilhada como "[...] o processo de compartilhamento de responsabilidades $e$ atribuiçóes entre representantes do Estado e da sociedade civil organizada visando subsidiar a elaboração e implementação de normas, critérios, padróes e medidas para o uso sustentável dos recursos pesqueiros". E sistema de gestão compartilhada como "[...] sistema de compartilhamento de responsabilidades $e$ atribuiçóes entre representantes do Estado e da sociedade civil organizada, formado por comitês, câmaras técnicas e grupos de trabalho de caráter consultivo e de assessoramento, constituidos por órgáos do governo de gestão de recursos pesqueiros e pela sociedade formalmente organizada".

Nolevantamentodasiniciativas degestão compartilhada no Brasil, realizado por Seixas \& Kalikoski (2009), foi observado que nas diversas regióes do país têm ocorrido experiências de gestão pesqueira com a participação de pescadores. Como exemplos têm-se: Reserva de Desenvolvimento Sustentável de Mamirauá, (Estado do Amazonas) e Reseva Estrativista Marinha Arraial do Cabo, (Estado do Rio de Janeiro), que são arranjos de gestão compartilhada com funcionamento dentro de unidades de conservação; os acordos de pesca que tem sido implementados em diversas regiôes na Amazônia, como as reservas de lago e manejo comunitário no baixo Amazonas, nas Ilha de São Miguel e Aracampina e o Projeto Várzea - na região de Santarém (Estado do Pará) (Seixas \& Kalikoski, 2009).

Dentre os diversos sistemas de gestão com compartilhamento de decisóes encontrados no Brasil, estão os Fóruns de pesca. Estes são arranjos institucionais nos quais participam as comunidades locais, colônias e sindicatos de pesca, e ainda representantes de organizaçóes governamentais e não governamentais, buscando um dialogo entre as partes para ordenar as atividades humanas nestes locais, buscando um processo de gestão descentralizado e participativo através da integração de diferentes esferas (Kalikoski et al, 2006).

No estado do Rio Grande do Sul existem algumas iniciativas de sistemas de gestão compartilhada da pesca artesanal, através de Fóruns de Pesca. São estes: Conselho Cooperativo para Açóes na Lagoa Mirim no Âmbito Pesqueiro - COMIRIM, que surge a partir de 1992, com o objetivo do ordenamento pesqueiro das Lagoas Mirim, Mangueira e afluentes; Fórum da Lagoa dos Patos, que começa a se reunir em 1996, em função da queda dos estoques pesqueiros da região, principalmente o camarão (Farfantepeneauspaulensis); Fórum de Gestão da Pesca na Bacia do Rio Uruguai, que surge em 2008 através de convênios executados entre a Fidene/ Unijuí e SEAP/PR, que têm reunido os pescadores da região do Rio Uruguai; Fórum do Delta do Jacuí e Guaíba, criado recentemente, porém construindo a discussão sobre gestão compartilhada na região desde 2009; e o Fórum da Pesca do Litoral Norte.

Com o objetivo de realizar um diálogo integrado, sobre os problemas que envolvem a pesca artesanal no Litoral Norte do Rio Grande do Sul, em 2003 instalou-se nesta região o Fórum de Pesca do Litoral Norte. A atividade da pesca de subsistência e artesanal nessa região é realizada nas praias da faixa litorânea, nas lagoas internas de água doce de Itapeva, Quadros, Malvas, Pinguela, Fortaleza, Cidreira,
Laguna dos Patos; e no estuário da lagoa de Tramandaí e Custódia. Nestes diversos corpos hídricos encontram-se comunidades de pescadores que utilizam os recursos naturais locais, explorando as áreas terrestres, úmidas e aquáticas, sendo historicamente dependentes da pesca artesanal para a sua subsistência (Garcez \& Sanches-Botero, 2005).

O modo de vida destas populações de pescadores artesanais tem sido fortemente influenciado por transformaçóes socioambientais que ocorreram nas últimas décadas. Entre os fatores que trouxeram prejuízo à pesca artesanal estão o crescimento urbano e o avanço do turismo sobre zonas ciliares da lagoa de Itapeva, dos Barros, Armazém e da Laguna de Tramandaí e sobre os sistemas de banhados e dunas na zona marítima em todos os municípios que compóem o Litoral Norte. Outros fatores como a expansão das lavouras de arroz irrigado sobre os campos úmidos e banhados, o uso de agrotóxicos nas lavouras hortifrutigranjeiras, a atividade de mineração, poluição química e industrial e a sobrepesca vêm trazendo sérios danos à fauna aquática, impedindo a reprodução e desenvolvimento da ictiofauna local e promovendo a redução dos estoques pesqueiros (Cotrim, 2008).

O estabelecimento da Instrução Normativa IN 17/2004 (D.O.U., 2004), construída por meio de um processo participativo que incluiu pescadores, Empresa de Assistência Técnica e Extensão Rural /EMATER-RS e Instituto Brasileiro do Meio Ambiente e dos Recursos Naturais Renováveis/ IBAMA, estabeleceu a formação de um Fórum da Bacia do Rio Tramandaí, que visou coordenar os ajustes da mesma. Apesar de ter origem num processo de integração entre várias esferas, este Fórum não se perpetuou. No entanto, após este processo, entendendo a importância da criação deste espaço, o Movimento dos Pescadores Profissionais Artesanais, presente na região, com o apoio de prefeituras locais e do Ministério da Pesca e Aquicultura, promoveu o estabelecimento de um novo Fórum, denominado então, de Fórum de Pesca do Litoral Norte.

Atualmente, o Fórum de Pesca do Litoral Norte está em sua quarta gestão administrativa e se constitui em um espaço de diálogo entre atores sociais, que busca discutir questóes relacionadas à gestão do território de pesca do litoral norte, às dificuldades e às demandas dos pescadores e aos conflitos com outros usuários destes espaços. Diversos atores participam do Fórum, além das associações, sindicatos e colônias de pescadores, que articulam a presença dos pescadores nas reuniōes. Há também a participação governamental, com a presença do IBAMA, Secretaria do Desenvolvimento Rural/ SDR por meio do Departamento Estadual de Pesca e Aquicultura, EMATER, Ministério da Pesca e Aquicultura/ MPA, Universidade Federal do Rio Grande do Sul/UFRGS, por meio do Núcleo de Estudos em Desenvolvimento Rural Sustentável e Mata Atlântica/ DESMA, Comando Ambiental da Brigada Militar/ CABM, entre outros.

Este artigo tem como objetivo analisar a gestão do Fórum de Pesca do Litoral Norte do Rio Grande do Sul, com ênfase em sua capacidade de articulação e encaminhamento das questóes da pesca profissional artesanal em ambientes lacustres, estuarinos e marítimos. 


\section{MATERIAIS E MÉTODOS}

A presente pesquisa foi realizada por meio de um estudo de caso da gestáo compartilhada dos ambientes pesqueiros na regiáo do litoral norte do Rio Grande do Sul (Figura 1). A pesquisa caracterizou-se por uma abordagem qualitativa, no âmbito de uma pesquisa-ação (Kubo et al., 2009). A coleta de dados, por sua vez, foi realizada em dois espaços de análise, sendo o primeiro o Fórum da Pesca do Litoral Norte e o segundo encontros promovidos por esta pesquisa nas comunidades de pescadores artesanais do Litoral Norte.

No âmbito do Fórum da Pesca, foram acompanhadas as nove reunióes ocorridas entre o período de setembro de 2011 a outubro de 2012. O número de participantes variou entre 30 a 60 pessoas por reunião, incluindo pescadores artesanais, técnicos extensionistas, representantes de órgãos públicos e pesquisadores. Os dados foram coletados através das técnicas de observaçáo participante, diário de campo (Viertler, 2002) e análise documental das atas das reunióes anteriores, desde 2011 até 2012.

Nas comunidades de pescadores, foram promovidos, em parceria com o Fórum da Pesca e a ONG Ação Nascente Maquiné/ANAMA, três encontros, no mês de agosto de 2012, com o objetivo de discutir os problemas da pesca artesanal nas diferentes regióes do litoral norte. Os encontros foram realizados nos municípios de Balneário Pinhal, Tramandaí e no distrito de Arroio Teixeira, pertencente a Capão da Canoa, onde participaram 20, 14 e 12 pescadores artesanais, respectivamente, contemplando a representatividade da regiấo.

Para a coleta de dados foi utilizada metodologia participativa (Kubo, 2009), por meio das técnicas de árvore dos problemas combinada com o censo de problemas de uso de recursos, que tiveram como objetivo identificar, a partir da perspectiva das comunidades, os problemas existentes no acesso e uso dos recursos naturais (Geilfus, 1997). A metodologia permitiu a organização dos problemas e demandas elencados ao longo das diferentes etapas, os quais foram expressos na forma de tarjetas, ao mesmo tempo, em que foi feita a sistematização de todo o encontro, abarcando as discussóes realizadas entre os atores a partir das diferentes questóes pautadas (Kubo, 2009).

A análise dos dados foi realizada a partir da análise de conteúdo (Bardin, 1977) de modo a identificar e sistematizar os problemas e demandas elencados pelos pescadores artesanais, da região do Litoral Norte e suas concepções acerca das questôes discutidas. Buscou-se compreender este debate no âmbito do Fórum de Pesca do Litoral Norte, com ênfase em sua capacidade de articulação e encaminhamento das questóes da pesca profissional artesanal em ambientes lagustres, estuarinos e marítimos.

\section{RESULTADOS E DISCUSSÃO}

A participação dos pescadores artesanais no processo de gestáo: identificação das questões sobre dificuldades na pesca nos ambientes lagunares, estuarinos e marítimos

Os encontros locais para discutir as questóes da pesca artesanal foram articulados com o intuito de incentivar e promover a maior participação de pescadores das diversas regiôes do Litoral Norte gaúcho nas discussōes referentes à gestão dos ambientes pesqueiros, buscando instigar e estimular estes atores a estarem presentes e se posicionarem em espaços de diálogo, como no Fórum.

Os assuntos debatidos nos três encontros foram sistematizados em torno dos temas: pesca em ambientes lagunares e estuarinos (questôes ambientais, fiscalização, legislação ambiental, conflitos territoriais e com outras categorias de usuários) e marítimo (questóes ambientais e conflitos territoriais) e questóes gerais dos pescadores profissionais artesanais (burocracia para documentação e acesso a programas e valorizaçáo da pesca artesanal), conforme o Quadro 1.

\section{QUESTÓES NA PESCA LAGUNAR E ESTUARINA}

Diversos problemas ambientais foram identificados nos ambientes de pesca lagunar e estuarino, dentre eles a diminuição dos estoques pesqueiros, que segundo os pescadores, estão associados a inúmeros fatores. Nas lagoas são apontadas as causas como a pesca predatória no período de piracema; o esforço de pesca maior do que a capacidade de suporte do ambiente e a poluição das águas por agrotóxico e esgoto causando mortalidade, contaminação e até deformação do pescado.

A construção de barragens nas lagoas e a drenagem dos banhados e lagoas para outras atividades, principalmente o cultivo de arroz, foi outro problema levantado. Os pescadores explanam que este processo vem provocando a mudança no curso dos cardumes, impedindo a entrada dos mesmos, além de promover a seca de muitos banhados e a diminuição da quantidade de água nas lagoas próximas. Estes ecossistemas foram depredados, provocando o desaparecimento de muitas espécies animais, como o ratáo-do-banhado, capivara, lontra e aves que ali frequentavam; estes ambientes são berçários para os peixes e a destruição dos mesmos vem acarretando uma diminuição drástica na quantidade de peixes que se desenvolviam nestes ambientes.

$\mathrm{O}$ assoreamento dos rios e arroios também é mencionado e como causa é apontada a mudança do curso natural de córregos, trazendo consequências ao fluxo de entrada ou saída dos cardumes. A destruição dos juncais (Schoenoplectus californicus (C.A.Mey.) Soják) e outras macrófitas aquáticas existentes nas lagoas é resultado do corte ilegal das malhas de junco, próximas aos terrenos dos proprietários, bem como da atividade pecuária nas margens, o que promove um pisoteio do gado sobre o junco. De acordo com os pescadores, este problema também se traduz em um empecilho para o desenvolvimento dos alevinos da traíra, que têm no junco e outras macrófitas seus locais de abrigo e crescimento. Aretirada desta vegetação também vem causando o assoreamento das lagoas e arroios, trazendo dificuldades, tanto para os cardumes quanto para os pescadores se locomoverem.

A legislação ambiental e a fiscalização foram temáticas recorrentes nos espaços de análise. De acordo com os pescadores, a fiscalização deixa lacunas a serem preenchidas e muitos dos aspectos da legislaçáo ambiental estão em desacordo com as realidades socioambientais locais. A Instrução Normativa $n^{\circ} 17 / 2004$ (D.O.U., 2004), que regulamenta a pesca na Bacia Hidrográfica do Rio Tramandaí, apesar de ter sido construída por meio de um processo em 


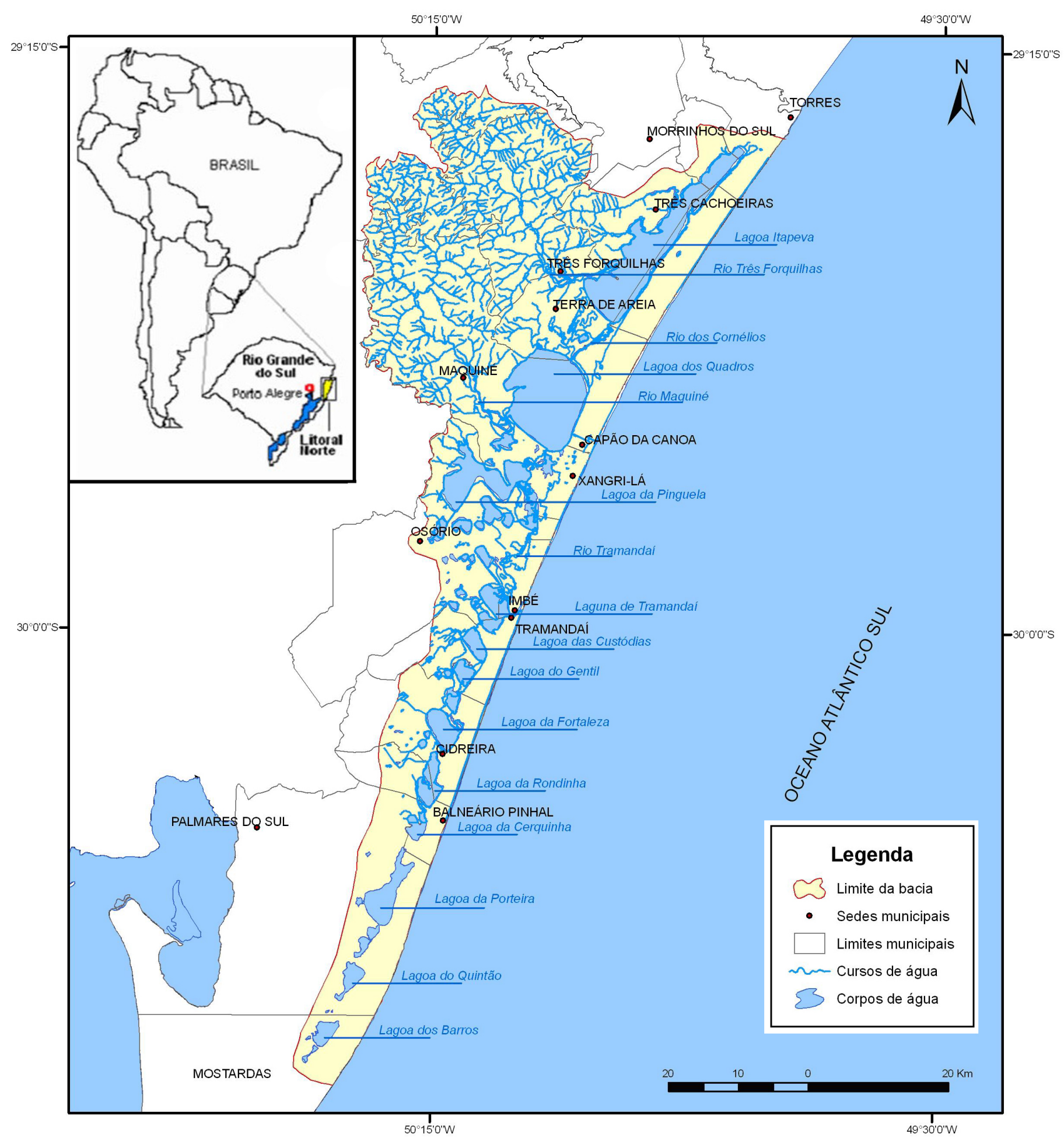

Figura 1: Mapa das regiōes abrangentes do Fórum de Pesca e dos encontros promovidos com a participação dos pescadores. Fonte: http:// faunalitoral.blogspot.com.br/

Figure 1: Map of regions Comprehensive Fishing Forum and promoted meetings with participation of fisherman. Source: http://faunalitoral.blogspot.com.br/ 
Tabela 1. Questóes identificadas pelos pescadores profissionais artesanais sobre as dificuldades na pesca nos ambientes lacunares, estuarinos e marítimos.

Table 1. Issues identified by artisanal fisherman on the difficulties in the lacunar, estuarine and marine environments.

\begin{tabular}{|c|c|c|c|}
\hline & $\begin{array}{c}\text { AMBIENTES LACUNARES } \\
\text { E ESTARINOS }\end{array}$ & AMBIENTE MARÍTIMO & $\begin{array}{l}\text { QUESTÓES COMUNS À } \\
\text { PESCA NOS AMBIENTES }\end{array}$ \\
\hline \multirow{3}{*}{ AMBIENTAIS } & $\begin{array}{l}\text { Destruição dos Juncais } \\
\text { Drenagem dos banhados }\end{array}$ & Arrastão por barcos industrias & $\begin{array}{l}\text { Diminuição e escassez do } \\
\text { pescado }\end{array}$ \\
\hline & $\begin{array}{l}\text { Assoreamento dos rios, lagoas } \\
\text { e arroios }\end{array}$ & $\begin{array}{l}\text { Depredação e retirada de } \\
\text { marisco fora do tamanho }\end{array}$ & $\begin{array}{l}\text { Poluição dos ambientes por } \\
\text { resíduos sólidos, esgoto e } \\
\text { agrotóxicos }\end{array}$ \\
\hline & $\begin{array}{l}\text { Comporta fechada na Lagoa } \\
\text { do Magistério e Lagoa da } \\
\text { Cidreira }\end{array}$ & $\begin{array}{l}\text { Derramamento de óleo por } \\
\text { empresas que exploram } \\
\text { petróleo }\end{array}$ & \\
\hline \multirow{6}{*}{$\begin{array}{l}\text { FISCALIZAÇÃO } \\
\text { e LEGISLAÇÃO } \\
\text { AMBIENTAL }\end{array}$} & $\begin{array}{l}\text { Falta de fiscalização da pesca } \\
\text { nas lagoas, principalmente no } \\
\text { período de piracema }\end{array}$ & $\begin{array}{l}\text { Falta de ordenamento das } \\
\text { atividades da orla marítica } \\
\text { (pesca, esportes, lazer) }\end{array}$ & $\begin{array}{l}\text { Falta de fiscalização para } \\
\text { esportes náuticos em local de } \\
\text { pesca }\end{array}$ \\
\hline & $\begin{array}{l}\text { IN } 17 \text { responsável pelo } \\
\text { ordenamento da pesca defasada } \\
\text { sem incluir as características de } \\
\text { cada pescado, regramento dos } \\
\text { locais de pesca }\end{array}$ & $\begin{array}{l}\text { Falta de fiscalização para pesca } \\
\text { industrial }\end{array}$ & $\begin{array}{l}\text { Roubo e depredação de } \\
\text { material de pesca }\end{array}$ \\
\hline & $\begin{array}{l}\text { Falta de regramento para } \\
\text { drenagem de água para } \\
\text { produção de arroz }\end{array}$ & $\begin{array}{l}\text { Proibição da pesca da viola e } \\
\text { caçáo }\end{array}$ & $\begin{array}{l}\text { Falta de respeito aos } \\
\text { pescadores no momento } \\
\text { da fiscalização, realizada } \\
\text { por fiscais não orientados } \\
\text { corretamente sobre leis e } \\
\text { realidades locais }\end{array}$ \\
\hline & $\begin{array}{l}\text { Proibição da pesca na foz do } \\
\text { Tramandaí }\end{array}$ & $\begin{array}{l}\text { Falta de fiscalização onde há } \\
\text { ordenamento }\end{array}$ & $\begin{array}{l}\text { Falta de atendimento às } \\
\text { denúncias }\end{array}$ \\
\hline & $\begin{array}{l}\text { Proibição da pesca na lagoa do } \\
\text { Gentil }\end{array}$ & & \\
\hline & $\begin{array}{l}\text { Período de piracema de } \\
\text { algumas espécies não está de } \\
\text { acordo com o ciclo reprodutivo }\end{array}$ & & \\
\hline \multirow{3}{*}{$\begin{array}{l}\text { CONFLITOS } \\
\text { TERRITORIAIS }\end{array}$} & $\begin{array}{l}\text { Dificuldade de acesso aos } \\
\text { ambientes de pesca de beira } \\
\text { de lagoa pela existência de } \\
\text { condomínios e colocaçáo de } \\
\text { cercas por fazendeiros }\end{array}$ & Conflitos com surfistas & Avanço da urbanização \\
\hline & Redes irregulares & & \\
\hline & $\begin{array}{l}\text { Embarcações e esportes } \\
\text { náuticos na foz do Tramandaí }\end{array}$ & $\begin{array}{l}\text { Pescador impedito de morar } \\
\text { na orla marítima, próximo ao } \\
\text { seu local de pesca }\end{array}$ & $\begin{array}{l}\text { Pesca amadora em conflito } \\
\text { com o espaço do pescador } \\
\text { local }\end{array}$ \\
\hline \multirow{3}{*}{ BUROCRÁTICAS } & & $\begin{array}{l}\text { Pescador de mar náo tem } \\
\text { direito ao seguro defeso }\end{array}$ & $\begin{array}{l}\text { Grande número } \\
\text { de pescadores sem } \\
\text { documentação necessária }\end{array}$ \\
\hline & & $\begin{array}{l}\text { Acordo com prefeituras de não } \\
\text { pescar no verão em funçáo do } \\
\text { turismo }\end{array}$ & $\begin{array}{l}\text { Burocracias no acesso a } \\
\text { programas sociais e a crédito }\end{array}$ \\
\hline & & & Carteiras de pesca irregulares \\
\hline
\end{tabular}


que houve a participação dos pescadores, apresenta algumas falhas. Existe um longo debate, dentro do Fórum de pesca do Litoral Norte, para que a mesma seja revisada.

De acordo com os pescadores, os pontos mais críticos e que necessitam de mudanças, são o período de defeso, que está em desacordo com o ciclo reprodutivo de algumas espécies, e a proibição da pesca na Lagoa do Gentil e na foz do Rio Tramandaí, que restringe ainda mais os locais de pesca. Os pescadores sugerem como alternativa para aliar conservação ambiental a atividade de pesca na Lagoa do Gentil, que a mesma seja liberada aos pescadores artesanais praticarem a atividade apenas nos meses de junho a agosto. Segundo eles, esta seria uma opção viável, pois o esforço de pesca não prejudicaria a ictiofauna e concomitantemente promoveria a manutenção da tradicional pesca de inverno nesta lagoa.

A fiscalização é falha nas lagoas, principalmente no período de piracema, quando ocorrem duas situaçóes predatórias. A primeira é a pesca amadora ilegal com redes de malha menor do que $8 \mathrm{~cm}$, tamanho permitido, sendo que esta ação também foi denunciada como praticada por alguns pescadores artesanais. A segunda é o uso não ordenado de jet-skis, que trafegam sobre as malhas de junco ou provocam grande movimentação na água prejudicando a desova ou o desenvolvimento dos alevinos. Segundo os pescadores estas questôes poderiam ser evitadas se houvesse fiscalização rigorosa sobre todos os usuários dos ambientes lacustres, uma legislação ambiental que estivesse de acordo com as realidades e mudanças ambientais locais e a participação dos pescadores, tanto na formulação das leis, quanto no ato de fiscalizar. Os pescadores relatam que inúmeras vezes denunciaram estas infraçóes às autoridades competentes pela fiscalização, mas que em $90 \%$ dos casos, não houve retorno dos órgãos responsáveis. Tal situação além de incentivar estas infraçōes, uma vez que raramente pune os infratores, promove também um desestímulo à participação dos pescadores na fiscalização.

Em relaçáo aos conflitos territoriais destaca-se a dificuldade de acesso aos ambientes de pesca, em funçấo do grande avanço da expansão imobiliária sobre as margens das lagoas no Litoral Norte. A privatização destes espaços impede que os pescadores possam se locomover aos pontos de pesca ou ocupar as margens para descanso ou para proteçáo em momentos de navegação em condições na adequadas.

\section{QUESTÓES NA PESCA MARÍTIMA}

As questóes ambientais que incidem sobre o mar são a poluição, pesca predatória e exploração predatória do marisco. Quanto à poluição por resíduos sólidos, os pescadores apontam como causas a falta de conscientização das pessoas para o seu descarte e o rejeite de resíduos pelos navios de grande porte. Como consequência ocorrem danos à rede de pesca, na qual os detritos se concentram, também o fato de os peixes "escaparem" da rede, pois segundo os pescadores avistam os resíduos.

A pesca industrial é apontada como uma das atividades mais nocivas ao ambiente marítimo pesqueiro. Além de ser praticada uma pesca predatória, os barcos ultrapassam a distância permitida, invadindo o espaço exclusivo para pesca artesanal, e raramente são abordados pela fiscalização.
O chamado "arrastão" é feito pelos barcos industriais ou empresariais, trazendo danos aos ecossistemas, uma vez que esta técnica promove a sobrepesca, além de provocar a suspensão de sedimentos e impactar a fauna bentônica.

De acordo com Haimovici \& Mendonça (1996), a pesca de arrasto é considerada predatória danificando substancialmente as comunidades bentônicas. Em pesquisa realizada na plataforma continental do Rio Grande do Sul, sobre os descartes de fauna acompanhante na pesca de arrasto, os autores citam que a rejeição média de peixes foi estimada em 38,8 quilos por hora de arrasto, representando $52,3 \%$ da captura total. Conforme os pescadores, quando feitos os arrastóes, os pescadores artesanais precisam esperar até três semanas até o retorno de novos cardumes.

Sobre o marisco, o extrativismo tem como finalidade a alimentação ou comercialização, se constituindo em uma atividade bastante comum na região, sendo realizada principalmente pelas mulheres pescadoras. Durante o verão, a coleta também é realizada por veranistas, que praticam a atividade, depredando ou coletando os indivíduos ainda muito jovens, o que interfere nos estoques de mariscos que seriam coletados pelos pescadores nos meses posteriores. Essa perspectiva foi apresentada pelos pescadores ao longo dos encontros, não existindo, até o momento, pesquisas que avaliem a sustentabilidade desse extrativismo.

Os conflitos por territórios se configuram a partir dos diferentes usos da orla marítima, uma vez que em alguns pontos ainda não ocorreu o ordenamento pesqueiro, como exige a lei $n^{\circ} 13.660 / 2011$ (D.O.E., 2001), que determina a obrigatoriedade de demarcaçáo das áreas de pesca, lazer ou recreação, nos municípios com orla marítima, lacustre ou fluvial. Onde há demarcação destas áreas, os participantes observam que a fiscalização é mais rigorosa para com os pescadores, sendo que outras categorias comumente ultrapassam as áreas demarcadas e usufruem também da área exclusiva para a pesca artesanal, como o surf, por exemplo. Este fato foi citado em cinco reuniôes do Fórum e nos três encontros com as comunidades de pescadores da regiāo do Litoral Norte.

\section{QUESTÓES COMUNS AOS AMBIENTES DE PESCA}

Os pescadores identificam algumas questóes da pesca profissional artesanal comuns tanto aos ambientes lagunares e estuarinos, quanto aos ambientes marítimos. Os conflitos por roubo e depredação de material de pesca, que trazem prejuízo aos pescadores. O elevado número de carteiras de pesca irregulares, que segundo Costa (2007) é um problema existente em todo território brasileiro. Poucas pesquisas nos ambientes e não retorno daquelas realizadas, sendo que são sugeridas pesquisas sobre a ecologia viola, a respeito dos estoques do cação e sobre as causas da mortalidade de marisco. O elevado número de pescadores sem documentação e dificuldade de acesso a programas sociais e ao crédito. Os pescadores mencionam que existe uma grande burocracia tanto para se regulamentar enquanto pescador, o que precisa de diversas licenças, quanto para acessar programas sociais, $o$ que muitas vezes impede que os mesmos sejam beneficiários destas políticas. 
Vasconcelos et al. (2007) identificam uma crise no setor pesqueiro, que ocorre por fatores externos, como a urbanização desenfreada sobre os territórios de pesca, e fatores internos, como a falta de organizaçáo institucional tanto interna, dos pescadores, quanto de instituições envolvidas com a pesca. Os pescadores reconhecem esta problemática e identificam que o avanço da ocupação urbana sobre seus espaços prejudica a reprodução social e o modo de vida da categoria. Fazem uma crítica à desvalorização do pescador artesanal profissional e da mulher pescadora pela sociedade. Existe também uma preocupação com a descontinuidade da categoria, que é consequência desta crise, em que o pescador sofre diversas intempéries, promovendo um desestímulo às próximas geraçôes, que acabam por desistir da atividade na pesca e passam a ocupar outros espaços dentro da sociedade. $\mathrm{E}$, por último, mencionam a insuficiente uniâo entre a categoria e a baixa participaçáo dos pescadores nos espaços de tomada de decisão.

Para resolver ou amenizar esta problemática, os pescadores sugerem a criação de novos espaços institucionais que trabalhem com as questóes da pesca, como por exemplo, uma superintendência regional da pesca. Foram também apontados meios que proporcionem uma maior valorização da categoria e a garantia de sua reproduçáo social, como a criação do Território da Pesca, o reconhecimento das associaçóes como entidades representativas da categoria, a capacitação técnica (ex. apropriação de leis, informática) aos membros das associaçôes e a criação de uma federação das associações de pescadores.

\section{ARTICULAÇÃO E ENCAMINHAMENTO DAS QUESTÓES DA PESCA PROFISSIONAL ARTESANAL}

As questóes da pesca profissional artesanal, identificadas no espaço dos encontros estáo em consonância com os temas comumente debatidos e encaminhados no Fórum de Pesca do Litoral Norte. Dentre as questóes identificadas nos encontros com os pescadores, sobre as quais já existe um trabalho de articulação e encaminhamento no âmbito do Fórum, destacam-se: a) das ambientais: a situação das comportas e do derramamento de óleo; b) daquelas referentes a fiscalização e legislação: a capacitação dos fiscais, a revisão dos critérios técnicos para o ordenamento pesqueiro e o ordenamento da orla marítima; c) das burocráticas: esclarecimentos sobre documentação para pesca profissional artesanal e revisão de acordos com prefeituras sobre pesca no verão.

Em relação às comportas, o Fórum recebeu um abaixo assinado elaborado pela Associação dos Pescadores do Bairro Tirolesa, do município de Tramandaí, se manifestando contra uma comporta construída para a produção de arroz na Lagoa da Fortaleza, a qual impede a circulação dos peixes e alevinos. O Fórum, ao receber tal demanda, encaminhou uma cópia ao Comitê Estadual da Bacia Hidrográfica do Rio Tramandaí, para que este auxiliasse na mediação do conflito. Embora o Fórum tenha encaminhado a questão, ele não mais obteve retorno dos seus desdobramentos, evidenciando a falta de articulação entre os colegiados.

Ainda sobre as questôes ambientais, em 2012, após o derramamento de óleo na faixa marítima de Tramandaí, o Fórum elaborou um oficio destinado ao Ministério Público Estadual solicitando providências às entidades competentes para prevençấo deste tipo de acidente e solicitando recursos para compensação dos prejuízos à pesca e turismo na regiáo. Sobre este encaminhamento o único retorno, foi um esclarecimento do representante do IBAMA durante uma reunião, que dizia respeito às sançóes que a empresa responsável pelo acidente receberia, as quais seriam: multa administrativa e obrigação de reparo socioambiental.

A capacitação dos fiscais sobre a legislação da pesca e ordenamento territorial foi um dos temas trabalhados em 2012 pelo Fórum, conjuntamente com a Secretaria Estadual de Desenvolvimento Rural, Pesca e Cooperativismo (SDR). Foi organizado um curso direcionado à capacitação dos servidores das secretarias da Segurança Pública (Brigada Militar, Polícia Civil, Batalhão Rodoviário Estadual) que atuam sobre a fiscalização, com a participação de pescadores de diversas regióes que fizeram críticas e sugestôes para aperfeiçoar o processo de fiscalização.

Kalikoski \& Silva (2007) em estudo realizado no Fórum da Lagoa dos Patos observaram que para uma fiscalização mais efetiva é necessário que o Fórum desenvolva mecanismos de parceria com as comunidades locais, para que elas possam ser agentes ativos de fiscalização conjuntamente com os órgãos governamentais. Destacam, porém, que o sucesso depende de uma redistribuição e devolução de poder às comunidades locais por parte do governo. Segundo os autores, é necessário que sejam desenvolvidos mecanismos no sentido de delegar poderes e responsabilidades às comunidades de pescadores locais sobre o monitoramento e fiscalização das atividades pesqueiras e de outros aspectos relacionados à pesca, como por exemplo, os níveis de poluição da água. No caso do Fórum do Litoral Norte, este promoveu uma reunião com os órgãos fiscalizadores para discussão sobre a demanda de uma fiscalização efetiva e o atendimento das denúncias. Este foi o primeiro passo para uma participaçáo dos pescadores na fiscalização, sendo necessário, porém dar continuidade ao processo para que haja um empoderamento dos pescadores nesta atividade.

$\mathrm{O}$ ordenamento da pesca é pauta freqüente do Fórum, sendo motivo de criaçáo de grupos de trabalho. $\mathrm{O}$ primeiro foi formado em 2011, com o intuito de avançar em uma proposta de revisão dos critérios técnicos e padróes de uso para atividade da pesca na Bacia Hidrográfica do Rio Tramandaí, os quais são estabelecidos pela Instrução Normativa n ${ }^{\circ}$ 17/2004 (D.O.U., 2004). O segundo, criado também em 2011, tinha o comprometimento de discutir o Ordenamento Pesqueiro na orla marítima, que ainda não existe. No entanto, estes grupos, durante o período de 2011 a 2012, não se consolidaram. Por este motivo, em 2012, foram formados novos grupos de trabalho para retomar e avançar nestas questóes, sendo constituído pelas entidades públicas com poder de decisão, como o IBAMA, MPA, CABM, SDR, EMATER, UFRGS e associaçóes de pescadores. Nas reunióes do fórum, estes temas têm se tornado centrais nas discussóes, pois o ordenamento incide diretamente na viabilização da pesca, a partir da determinaçáo dos locais e períodos de pesca das diferentes espécies.

O outro assunto comum do Fórum é o ordenamento territorial, estabelecido pela Lei Estadual 13.660/2011 (D.O.E., 2011), que obriga a demarcação das áreas de pesca, lazer ou recreação em municípios com orla marítima, 
lacustre ou fluvial. Este processo está sendo realizado nos diferentes municípios do Litoral Norte, sendo objeto de reivindicação dos pescadores dos municípios nos quais ainda não tiveram o ordenamento estabelecido, bem como pauta de reivindicação de fiscalização dentre os municípios nos quais já está estabelecido. Esta questão é central para os conflitos territoriais, que se estabelecem entre esportistas de jet skis e pescadores, em ambientes lacustres, e surfistas, banhistas e pescadores, em ambientes marítimos. Como forma de encaminhar esta demanda o Fórum realizou uma reunião com a SDR, em 2011, e a partir desta, elaborou documento reivindicando que a regulamentação da lei garanta ressarcimento dos prejuízos das famílias que praticam a pesca do cabo, que pela demarcação das áreas de pesca, surf e lazer tiveram que deslocar seus pontos de pesca, dificultando a atividade cotidiana.

As questôes burocráticas são entraves que dificultam a vida cotidiana dos pescadores profissionais artesanais, as quais foram objeto de um grupo de trabalho no âmbito do Fórum. O principal tema estudado pelo grupo e apresentado em reunião no Fórum foi o uso do bloco de notas de produtor rural no contexto dos pescadores. Outra questão neste tema são os Registros Gerais de Pesca, gerenciados pelo Ministério da Pesca e Aquicultura. Esta instituição, em reunião do Fórum, esclareceu que os mesmos são vistoriados e quando não contemplam as exigências são recolhidos.

Em relação às prefeituras de municípios com orla marítima construiu-se, no âmbito do Fórum, a reivindicação da pesca não ser interrompida no veráo e ser liberada no período noturno nos pontos de surf e lazer, em alguns municípios. Este documento foi encaminhado para o Departamento de Pesca, Aquicultura, Quilombolas e Indígenas da SDR e para a comissáo instituída poder redigir a minuta de regulamentação. No entanto, no momento da construção da regulamentação da pesca nos municípios, dentre as já promulgadas, as reivindicaçóes não foram atendidas.

Diante desse contexto, depreende-se que as questóes levadas aos Fóruns são articuladas e encaminhadas, mas sem sucesso em suas resoluçôes. Essa situação, acrescida do fato dos temas se repetirem ao longo do tempo, leva os pescadores a desacreditarem no espaço de gestáo do Fórum como uma estrutura com competência para solucionar os entraves que prejudicam a pesca profissional artesanal. Por estas lacunas problemas e demandas locais acabam não sendo expostos, registrados e encaminhados. Dentre os fatores que originam a falta de credibilidade, destacam-se o fato de que muitas demandas exigem açóes intersetoriais, fazendo com que a capacidade de encaminhamento ultrapasse as competências dos órgáos governamentais representados, os quais estáo empreendendo um esforço para atuar de forma articulada. A questáo do ordenamento do território da pesca é o exemplo mais claro desta situação.

Ao mesmo tempo, os pescadores reconhecem o Fórum como um espaço de contato com os diversos atores envolvidos com a pesca, onde suas demandas são discutidas em um debate mais amplo com outros órgáos, a exemplo da questão da fiscalização, na qual os pescadores puderam explanar sua opiniáo acerca das mudanças necessárias para o processo de fiscalização ser mais eficiente. Também é positivo o fato de ser um espaço de esclarecimento das dúvidas dos pescadores, porém poucas demandas são solucionadas.
De acordo com os graus de participação estudados por Berkes (2005), o Fórum do Litoral Norte representa um caso intermediário entre a gestão realizada pelos órgãos governamentais e o manejo totalmente comunitário. Ainda que o Fórum de Pesca do Litoral Norte tenha possibilitado um aumento na participação das comunidades de pescadores na discussão sobre a gestão de seus territórios junto à esfera pública e órgáos locais, para que esta gestão tenha maior inserçâo junto às comunidades, esta participação precisa ser ampliada. No Fórum, a presença destes atores se faz sutilmente, geralmente com as reunióes sendo frequentadas pelas lideranças das comunidades e por alguns pescadores mais engajados.

\section{CONCLUSÁO}

Com o surgimento do Fórum de Pesca do Litoral Norte criou-se a possibilidade de um diálogo direto com entidades governamentais e o encaminhamento de demandas identificadas pelas comunidades de pescadores. No entanto, este Fórum apesar de ser considerado o mais organizado, quando comparado aos demais existentes no Rio Grande do Sul, está em processo contínuo de estruturação, buscando o atendimento das demandas trabalhadas no âmbito da gestão compartilhada.

Fatores que desencadeiam a necessidade de estruturação fundamentam-se no fato de que as questóes que são repetidamente discutidas, as quais são encaminhadas por meio de manifestações e articulações efetivadas pelo Fórum, ficam sem retorno de seus desdobramentos, como o ordenamento territorial e o ordenamento dos critérios da pesca, interferindo na credibilidade desse sistema de gestáo. Entretanto, o Fórum é reconhecido como o espaço de articulação e encaminhamento das questóes da categoria dos pescadores profissionais artesanais pelos pescadores e demais atores envolvidos na gestáo da pesca.

Conclui-se que o Fórum de Pesca do Litoral Norte do Rio Grande do Sul é um espaço de implementação da gestão compartilhada, o qual foi incentivado pelo governo e apropriado pela representaçâo dos pescadores, tendo a capacidade de articular as demandas dos pescadores artesanais de ambientes lacustres, estuarinos e marítimos da regiâo do Litoral Norte e encaminhar às instâncias competentes. Entretanto, por serem demandas associadas à gestão de recursos comuns e territórios compartilhados, os quais estão sendo apropriados por segmentos da sociedade respaldados pela lógica da propriedade privada, elas sáo tensionadas pelo arranjo institucional envolvido na gestão compartilhada, estando, atualmente, em disputa na sociedade.

\section{AGRADECIMENTOS}

Nossos agradecimentos ao Fórum de Pesca do Litoral Norte, ao pescador e líder Sr. Valdomiro Hoffmann, ao técnico da EMATER Delmar Dietz, aos pescadores participantes dos encontros, à acadêmica Camila Padilha Costa, à mestranda Viviane Camejo, à doutoranda Danielle Wagner Silva, do PGDR, ao Anselmo Kanaan, ao Dilton de Castro, Natavie Kaemmerer, ao Ricardo Silva Pereira Mello, da ONG ANAMA, à Petrobrás e ao CNPq. 


\section{BIBLIOGRAFIA}

Bardin, L. (1977) - Análise de Conteúdo. 223p., Persona, Lisboa, Portugal. ISBN: 978-8562928047.

Berkes, F. (2005) - Exxitos e fracassos na pesca costeira da Turquia. In.: Paulo F. Vieira, Fikret Berkes, Cristiana S. Seixas (org.), Gestão integrada e participativa dos recursos naturais - conceitos, métodos e experiências, pp.147-175, Secco/APPED, Florianópolis, SC, Brasil. ISBN: 8598128058.

Carlsson, L; Berkes, F. (2005) - Co-management concepts and methodological implications. Journal of Environmental Management. 75(1):65-76. DOI: 10.1016/j. jenvman.2004.11.008

Costa, A.L. (2007) - Os falsos Pescadores: supostas fragilidades na gestão pesqueira. In.: A.L. Costa (org.), Nas redes da pesca artesanal, pp.241-253, IBAMA, Brasília, DF, Brasil. ISBN: 978-8573002515.

Cotrim, D. (2008) - Agroecologia, sustentabilidade e os pescadores artesanais: $O$ caso de Tramandai (RS). 198p., Dissertação de Mestrado, Universidade Federal do Rio Grande do Sul, Porto Alegre, RS, Brasil. Não publicado.

D.O.E. (2011) - Lei no 13.660, de 12 de janeiro de 2011 Altera a Lei no 8.676, de 14 de julho de 1988, que determina a obrigatoriedade de demarcação das áreas de pesca, lazer ou recreação, nos municípios com orla marítima, lacustre ou fluvial. Diário Oficial do Estado, 13.01.2011, seção 010, p.1. Disponível em http://www.al.rs.gov.br/ legis/M010/M0100099.ASP?Hid_Tipo=TEXTO\&Hid_ Todas Normas $=55733 \&$ hTexto $=\&$ Hid_IDNorma $=55733$

D.O.U. (1988) - Lei no 7.661, de 16 de maio de 1988 Institui o Plano Nacional de Gerenciamento Costeiro e dá outras providências. Diário Oficial da União, 18.5.1998, seção 1, p.8633. Disponível em http://www.planalto.gov. br/ccivil_03/leis/L7661.htm

D.O.U. (2000) - Lei no 9985, de 18 de julho de 2000 institui o Sistema Nacional de Unidades de Conservação da Natureza e dá outras providências. Diário Oficial da União, 19.7.2000, seção1, p.1. Disponível em http://www. planalto.gov.br/ccivil_03/leis/L9985.htm

D.O.U. (2004) - Instruçáo Normativa $\mathrm{n}^{\circ} 17$, de 17 de outubro de 2004 - Estabelecer critérios técnicos e padróes de uso para a atividade da pesca na bacia hidrográfica do rio Tramandaí. Diário Oficial da União, 15.10.2004, seção 1, p.1. Disponível em http://www.ibama.gov.br/ category/40?download $=1281 \% 3 \mathrm{~A} \_-$_ $17 \_2004 . p$.

D.O.U. (2009a) - Decreto no 6.981, de 13 de outubro de 2009 - Dispóe sobre a atuação conjunta dos Ministérios da Pesca e Aquicultura e do Meio Ambiente nos aspectos relacionados ao uso sustentável dos recursos pesqueiros. Diário Oficial da União, 14.10.2009, seção 1, p.13. Disponível em http:// www.planalto.gov.br/ccivil_03/_Ato2007-2010/2009/ Decreto/D6981.htm

D.O.U. (2009b) - Portaria Interministerial MMA/MPA n ${ }^{\circ}$ 2, de 13 de novembro de 2009 - Regulamenta o Sistema de Gestâo Compartilhada do uso sustentável dos recursos pesqueiros. Diário Oficial da União, 16.11.2009, seção 1, p.63. Disponível em http://www.ibama.gov.br/sophia/ cnia/legislacao/MPA/PT0002-131109.PDF

Garcez, D.S.; Sánches-Botero, J.I. (2005) - Comunidades de pescadores artesanais no estado do Rio Grande do Sul. Revista Atlântica (ISSN:0102-1656), 27(1):17-29, Rio
Grande, RS, Brasil. Disponível em http://www.lei.furg.br/ atlantica/vol27/Numero1/ATL03.PDF

Geilfus, F. (1997) - 80 Herramientas para el Desarrollo Participativo: diagnóstico, planificación, monitoreo, evaluación. 208p., Editora Prochalate-IICA, San Salvador, El Salvador. http://www.mda.gov.br/o/890312 .

Haimovici, M; Mendonça, J.T. (1996) - Descartes da fauna acompanhante na pesca de arrasto de tangones dirigida a linguados e camaróes na plataforma continental do Sul do Brasil. Revista Atlântica (ISSN:0102-1656), 18:161177, Rio Grande, RS, Brasil. Disponível em http://www. demersais.furg.br/Files/1996.Haimovici.Mendonca. Descarte.tangone.Atlantida.pdf

Kalikoski, D.C; Silva, P.P. (2007) - Avanços e desafios na implementação da gestão compartilhada: liçôes comparativas do Fórum da Lagoa dos Patos (RS) e da Resex Marinha de Arraial do Cabo (RJ). In: A.L Costa (org.), Nas redes da pesca artesanal, pp.241-253, IBAMA, Brasília, DF, Brasil. ISBN: 978-8573002515.

Kalikoski, D.C., Rocha, R.D.; Vasconcellos, M.C. (2006) Importância do Conhecimento Ecológico Tradicional da Gestão da Pesca Artesanal No Estuário da Lagoa dos Patos, Extremo Sul do Brasil. Ambiente e Educação (ISSN: 14138638), 11(1):87-118, Rio Grande, RS, Brasil. Disponível em www.seer.furg.br/index.php/ambeduc/article/view/770

Kubo, R.R. (2009) - Metodologias participativas e sistematizaçáo de experiências. In: F. Dal Soglio \& R.R. Kubo (org.), Agricultura e sustentabilidade, pp.135-149, Editora da UFRGS, Porto Alegre, RS, Brasil. ISBN: 978-8538600749. Disponível em http://www.ufrgs.br/ cursopgdr/downloadsSerie/derad008.pdf

Kubo, R.R.; Terme, C.M.; Bassi, J.B.; Souza, G.C. (2009) - O tempo da construçáo de um trabalho: a pesquisa etnobiológica gerando pesquisa-ação. In: T.A.S. Araújo \& U.P. Albuquerque (org.), Encontros e desencontros na pesquisa etnobiológica e etnoecológica: os desafios do trabalho de campo, pp.11-42, NUPEEA, Recife, PE, Brasil. ISBN: 978-8577165469. Disponível em http://www.ufrgs.br/ pgdr/arquivos/635.pdf

Seixas, C.; Kalikoski, D.C. (2009) - Gestão participativa da pesca no Brasil: levantamento das iniciativas e documentação dos processos. Revista Desenvolvimento e Meio Ambiente (ISSN: 1518-952X), 20:119-139, Curitiba, PR, Brasil. Disponível em: http://ojs.c3sl.ufpr.br/ojs2/index.php/made/article/ download/12729/10947 .

Smith, A.H.; Berkes, F. (2005) - Uso comunitário de recursos no mangue em Santa Lúcia. In.: Vieira et al. (org.), Gestão integrada e participativa dos recursos naturais - conceitos, métodos e experiências, pp.177-190, Secco/APPED, Florianópolis, SC, Brasil. ISBN: 85-98128058.

Vasconcelos, M.; Diegues, A.C.; Sales, R.R. (2007) - Limites e possibilidades na gestáo da pesca artesanal costeira. In: A.L. Costa (org.), Nas redes da pesca artesanal, pp.241-253, IBAMA, Brasília, DF, Brasil. ISBN: 978-8573002515.

Viertler, R.B. (2002) - Métodos antropológicos como ferramenta para estudos em etnobiologia e etnoecologia. In: Maria Christina M. Amorozo, Chau M. Lin, Sandra M. P. Silva, (org.), Métodos de coleta e análise de dados em etnobiologia, etnoecologia e disciplinas correlatas, pp.11-30, Divisa Gráfica Editora, Rio Claro, SP, Brasil. ISBN: 8590243214. 